\title{
Water deficit sharing: A new approach to conflict resolution among stakeholders in the watershed
}

\author{
$\underline{\text { R. Roozbahani }}^{\mathrm{a}}$, S. Torabi Palatkaleh ${ }^{\mathrm{b}}$ and A. Karimic \\ ${ }^{a}$ School of Mathematical and Geospatial Science, RMIT University, Melbourne, Australia \\ Email:RezaRoozbahani@gmail.com \\ ${ }^{b}$ Water Planning Office, Ministry of Energy, Tehran, Iran \\ Email:Storabi@wrm.ir \\ ${ }^{c}$ Civil Engineering Dept., Islamic Azad University-East Tehran Branch, Tehran, Iran \\ Email:erajkarimi@gmail.com
}

\begin{abstract}
Population growth and socio-economic development make the competition for larger share in water allocation more intense among stakeholders in the watershed, which in turn brings up conflicts over the use and allocation of water. Competition for more shares of water between stakeholders, especially in dry areas, leads to over-exploitation of water resources and large deficits in supplying the downstream demands. Equitable allocation of water reduces conflicts among water allocation stakeholders, since it provides equal opportunity for water usage between them. Equitable sharing of deficits among upstream and downstream stakeholders is a promising approach to equitable water allocation. Karkheh watershed is a good example in which operation of very large dam in downstream is influenced largely by hydro-projects to be constructed by upstream stakeholders. Socio-economic development in dam upstream impairs reservoir operation and its capability in supplying water for downstream demands, which in turn brings up conflicts between upstream and downstream stakeholders about future developments in Karkheh watershed. This paper presents a new method for equitable allocation of water resources between different upstream and downstream stakeholders. It is based on mathematical simulation of catchment's hydro-system and evaluation of stakeholders' water usage on deficits upstream and downstream of the watershed. Deficits are distributed among stakeholders based on their share in deficits. Shared deficits are subtracted from each stakeholder target water demand to obtain equitable water allocation to each stakeholder. This approach is applied to Karkheh hydro-system for equitable water allocation in developed state of this watershed, which has developing upstream and developed downstream.
\end{abstract}

Keywords: $\quad$ Conflict resolution, equitable water allocation, water deficit sharing, stakeholders, water allocation criteria. 


\section{INTRODUCTION}

Water resources limitation, development requirements and stakeholders' competition for more profit diversifies and develops the conflict over water allocation in the watershed, temporally and spatially. Besides, water supply becomes much more complicated due to presence of resources limitation and conflicts over resources allocation. Conflict over water allocation can occur at local to international levels, since water becomes more valuable as it becomes scarcer. For resolution of conflict over water allocation, therefore, economic, social, political and environmental considerations must be involved in decision making.

Eleftheriadou and Mylopulous (2008) apply game theory to establishment of least conflict arousing strategy in sharing Nestos/Mesta River water resources between Greek and Bulgaria based on economic returns for both countries. Some recent studies incorporate stakeholders' utility functions in conjunction with game theories in the study of most acceptable water allocations (Ganji et al. 2008; Shirangi et al. 2008). Kampragouet al (2007) used Multi-Criteria Decision Making technique for most equitable water allocation of Nestos/Mesta River among its stakeholders, based on indices like; catchment's area, river runoff, water consumption per capita, population, unemployment ratio, water demand, inefficient use, GDP, and water stress index (WSI). Chermak et al. (2005) used cooperative, non-cooperative and myopic approaches to the optimum groundwater withdrawal planning that maximizes the stakeholders' socio-economic indices. Their analysis shows that cooperative approach leads to best value and Myopic approach leads to least favorable state for the stakeholders. Cai et al (2004) screened hydro-projects development scenarios in Jing-Jin-Tang region, north China, by MODM technique and used MCDM for ranking the reasonable sample of them. MCDM technique is used for equitable allocation of Jordan River water flow between Israel, Jordan, Palestine, Syria, and Lebanon by Mimi and Sawalhi (2003). Indicators such as; catchment's area, contribution to the river flow, current utilization, water demands, economic and social needs, future population, GDP and WSI are commonly used for quantification of stakeholders' benefits from resources utilization that can be used for quantification of equality in resources allocation. Nandala and Simonovic (2003) used system dynamics modeling for solving conflict between two stakeholders in a hypothetical water resources system.

Equitable water allocation is the main theme in most researches on conflict resolution, though not explicitly expressed. Application of Game theory, MCDM, MODM, system dynamics and other techniques is quantification of players' (stakeholders') preferences and their maximization in a manner that leads to maximum consensus. In this paper a new method for conflict resolution based on sharing water deficits between stakeholders is introduced and applied to a real world conflict resolution problem.

\section{WATER ALLOCATION IN IRAN}

Water allocation is very serious in Iran, due to non-integrated development pattern in watersheds. Developed downstream (with government investment) and under-development upstream is a common characteristic of most watersheds in Iran. To keep the balance between upstream and downstream development, due to increasing social problems, like; emigration from upstream, government issued many permits for constructions at the water basin upstream. It brought other social conflicts that can be summarized as:

1. Conflict between upstream and downstream stakeholders

2. Conflict among upstream stakeholders for having more share of limited upstream water resources

Therefore water allocation is becoming more complicated, since downstream water demands rely on upstream withdrawals. At the same time, upstream stakeholders try to get more allocation share from upstream resources. In this situations government wants to know, how benefits of water resources utilization must be shared equitably among the upstream and downstream stakeholders. Another important issue is the compromise between current downstream water rights and future upstream water demands in water allocation planning.

\section{KARKHEH WATERSHED}

Karkheh watershed contains 3\% of Iranian territory surface area and common boundaries with six western provinces from north to south of Iran (Fig. 1). These 6 provinces; Hamedan, Kordestan, Kermanshah, Lorestan, Eilam, and Khozestan, are the stakeholders of Karkheh watershed water resources allocation. The surface area and population of each province in the watershed are presented in table 1. In current study Kordestan provinces due to its small area is not considered in Karkheh watershed modeling. Main river of the basin is Karkheh River, which its head stream is located in Hamedan. It passes through Kermanshah, Lorestan, and Eilam, and at the end flows into Khozestan. The main dam in operation of the basin is Karkheh 
Roozbahani et al., Water Deficit Sharing: A New Approach to Conflict Resolution Among Stakeholders...

dam which is located in Khozestan province (downstream of basin).It supplies 2914 Million Cubic Meter (MCM)water for agricultural in Khozestan, $510 \mathrm{MCM}$ water for agriculture in Eilam (one of upstream provinces)and $1283 \mathrm{MCM}$ water environmental demands of dam's downstream. Karkheh dam specifications and location are presented in table 2 and figure 1. Inflow data to Karkheh dam from 1956 to 2005 is shown in figure 2. According to Karkheh dam simulation results, with $5558 \mathrm{MCM}$ long-term mean inflow, reservoir operation targets can be met with $90 \%$ volumetric and temporal reliability. Simulation results show that slacks in meeting Karkheh reservoir agricultural targets are within acceptable limits.

Traditional withdrawals in the upstream provinces sums up to $823 \mathrm{MCM}$ based on Iranian Ministry of Energy Database, which its detail by provinces and type of consumption are shown in table 3 .

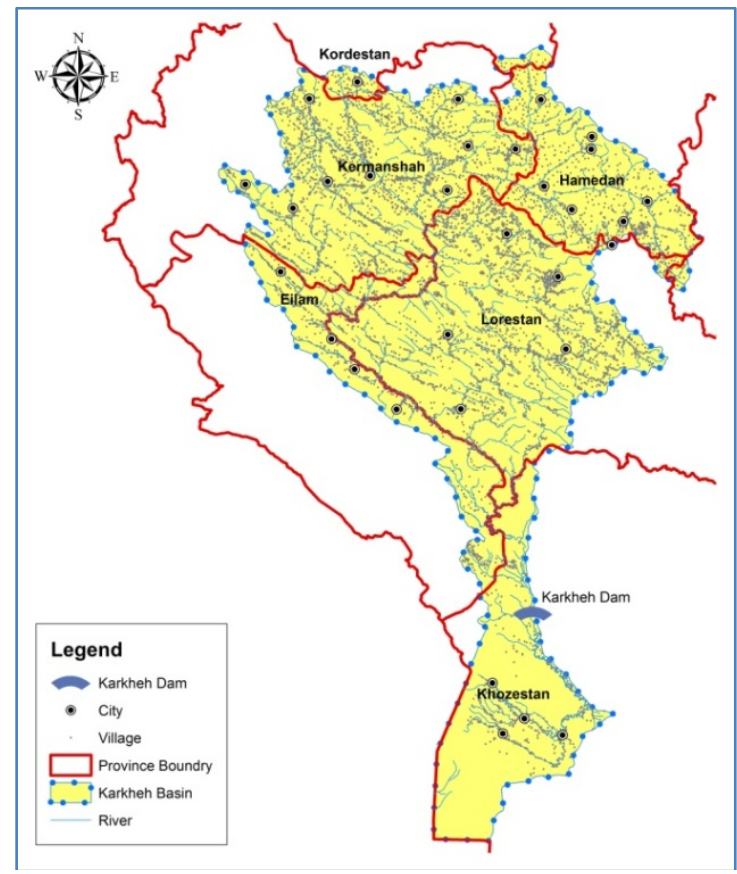

Figure 1.The stakeholders of Karkheh basin

Table 1.The area and population of each province in Karkheh Basin

\begin{tabular}{lll}
\hline Province & Area Contained in the Karkheh Waterbasin $\left(\mathrm{Km}^{2}\right)$ & Population 2006 \\
\hline Hamedan & 6821 & 624,562 \\
Kordestan & 729 & 68,937 \\
Kermanshah & 13433 & $1,454,079$ \\
Lorestan & 16713 & 943,883 \\
Eilam & 5363 & 133,937 \\
Khozestan & 9007 & 211,639 \\
Sum & 52065 & $3,437,037$ \\
\hline
\end{tabular}

Table 2.The characteristics of Karkheh Dam

\begin{tabular}{ll}
\hline Name & Karkheh Dam \\
\hline Targets & Agriculture, Environment, Hydropower \\
Name of River & Karkheh \\
Annual Inflow & 5558 \\
Active Reservoir Capacity (MCM) & 3840 \\
Regulated water volume (MCM) & 4707 \\
Agriculture (MCM) & 3424 \\
Environment (MCM) & 1283 \\
Total Hydropower Installed Capacity (Mega Watt) & 400 \\
Number of Turbines & 3 \\
State & Under Operation \\
\hline
\end{tabular}


Roozbahani et al., Water Deficit Sharing: A New Approach to Conflict Resolution Among Stakeholders...

Table 3.Traditional water withdrawals from Karkheh River in upstream provinces

\begin{tabular}{ll}
\hline Province & Traditional Agriculture Water Withdrawal (MCM) \\
\hline Hamedan & 251 \\
Kermanshah & 287 \\
Lorestan & 0 \\
Eilam & 285 \\
Sum & 823 \\
\hline
\end{tabular}

According to Iran Ministry of Energy Database, total water demands of upstream provinces in future sums up to $3576 \mathrm{MCM}$ that $1333 \mathrm{MCM}$ of it is currently used (traditional agriculture water withdrawal: $823 \mathrm{MCM}$, Eilam agricultural demand from Karkheh dam: $510 \mathrm{MCM}$ ) and it is planned to regulate remaining 2243 MCM by construction of new dams, which its detail by provinces and type of consumption are shown in table 4.

If all planned dams be constructed in Karkheh upstream, inflow to Karkheh dam and its capability in supplying the current downstream demands will decrease significantly. How water resources of Karkheh watershed should be allocated between upstream and downstream stakeholders to provide equitable opportunity for hydro-developments and prevent shortage in supplying different demands in downstream, is a challenge in Karkheh hydro-system planning.

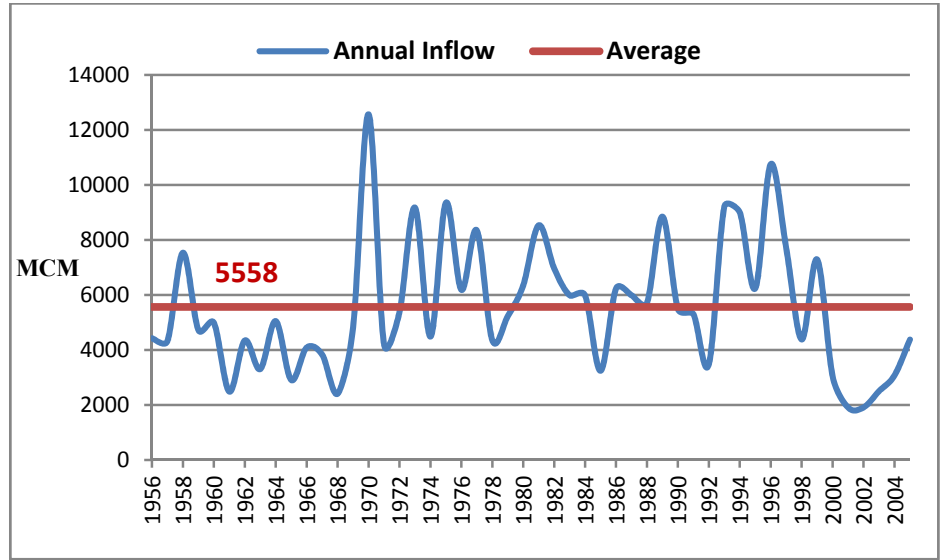

Figure2. Annual inflow of Karkheh Dam from 1956 to 2005

Table 4. New water demands for upstream stakeholders (MCM)

\begin{tabular}{llllll}
\hline Province & Domestic & Industry & Agriculture & Environment & Sum \\
\hline Hamedan & 24 & 7 & 90 & 39 & 159 \\
Kermanshah & 10 & 18 & 391 & 16 & 435 \\
Lorestan & 73 & 22 & 807 & 6 & 908 \\
Eilam & 25 & 7 & 690 & 18 & 740 \\
Sum & 132 & 54 & 1978 & 78 & 2243 \\
\hline
\end{tabular}

\section{PROPOSED METHOD}

Equity is defined as the same marginal costs (profits) for all stakeholders per additional allocated water [Dinar et al. 2005]. Equity normally within governmental attitude towards services to stakeholders is defined as equitable sharing of opportunities for utilization of resources, such as; water. It is not an economic oriented approach to resources allocation. It is very important to notice the equity as a social acceptability essence for decisions and rules rather than an economically efficient way for decision making. Social acceptability of decisions is proven to be a guarantee for application of economically efficient decisions or rules. In the context of Iranian socio-economic conditions, equitable water allocation balances upstream social costs with downstream economic benefits. Water allocation at upstream must be determined in a manner that has the least impacts on downstream water supply. In this research, equity is quantified as share of each stakeholder from deficits, which is decided up on by consensus between stakeholders. The practical method to obtain this consensus is holding session with them and collecting their views about the share ratios. Water allocation in this approach is implemented as:

1. Initial analysis of the hydro-system for determination of deficits at downstream 
Roozbahani et al., Water Deficit Sharing: A New Approach to Conflict Resolution Among Stakeholders...

2. Determination of deficit sharing ratios between upstream and downstream stakeholders. The ratio is determined by processing the session results held with upstream and downstream stakeholders.

3. Modification of water allocations based on results of initial analysis and deficit sharing ratios.

4. Determination of upstream stakeholders' water allocation share ratios based on consensus of upstream stakeholders on the water allocation ratios.

5. Upstream water allocation based on consensual ratios

According to the outlined water allocation method opportunities for upstream development is provided with the least costs for downstream water supply. Details of this approach to water allocation are explained as follows:

- Gathering the information: Information of all suggested projects in upstream and downstream must be gathered and each project simulation model should be prepared.

- Watershed system modeling: Based on hydro-system network and prepared simulation model for each project, hydro-system complete model must be developed including water withdrawal by stakeholders. By analysis of the hydro-system complete model, impacts of upstream projects operation on flow reduction at downstream projects and traditional water withdrawal points are estimated. This analysis shows whether initial goals of projects are met or not after construction of upstream projects. Besides, it shows water rights of traditional water users are met or not. At this step, conflicts are diagnosed and guidelines for resolving them can be thought out.In the watershed hydro-system model, this policy is followed that water must be allocated to municipal, industrial, environmental and agricultural demands respectively.

- Conflict resolution between upstream and downstream stakeholders: based on sessions with upstream and downstream provinces (stakeholders), consensus on the share of upstream and downstream must be called for as an equitable water allocation measurement. Watershed hydro-system model analysis shows the amount of deficits on downstream demands due to upstream withdrawals. This deficit in downstream is then divided between upstream and downstream based on consensual shares. In this study consensual shares are each stakeholder's demand ratio to total demand as shown in equation 1 and 2 .

$$
\begin{aligned}
& U D S=D I N \times \frac{T D U}{T D B} \\
& D D S=D I N \times \frac{T D D}{T D B}
\end{aligned}
$$

Wherein,

UDS: upstream deficit share (MCM)

DIN: deficit in downstream (MCM)

TDU: total demands of upstream (MCM)

TDB: total demands of basin (MCM)

DDS: downstream deficit share (MCM)

TDD: total demands of downstream (MCM)

After calculation of upstream and downstream stakeholders' share from deficits, water allocations are updated by subtracting the share of stakeholders' deficit from their total demands as shown in equations 3 and 4.

$$
\begin{aligned}
& W A U=T W D U-U D S \\
& W A D=T W D D-D D S
\end{aligned}
$$

Wherein,

WAU: water allocation of upstream (MCM)

TWDU: total water demands of upstream (MCM)

WAD: water allocation of downstream (MCM)

TWDD: total water demands of downstream (MCM) 
- At this stage, total water allocation to upstream is calculated and share of each stakeholder must be determined.

- Conflict resolution between upstream stakeholders: This part of water allocation method mainly deals with conflict resolution between upstream stakeholders after upstream modified total water allocation is determined. Himi and Sawalhi (2003) listed 9 water allocation indicators that can be used for equitable water allocation. In this method holding sessions with stakeholders, proposing different indicators to them, receiving their feedbacks and selecting the most favorable indicator (combination of indicators) is set forth as the conflicting resolution approach in water allocation. Therefore, based on many sessions and meetings with decision makers in each province (stakeholders), ratio of each province produced runoff to the total upstream runoff, was selected as water allocation indicator at upstream in this research. Therefore, water allocation to each stakeholder is calculated as shown in equation 5.

$W A P=W A U \times \frac{R P P}{T R P U}$

Wherein,

WAP: water allocated to each province (MCM)

RPP: runoff produced in province (MCM)

TRPU: total runoff produced in upstream (MCM)

In this study, VENSIM software is used for preparing project and basin simulation models. VENSIM is simulation software capable of simulating the dynamic behavior of systems with complexities, such as; feedbacks, based on causality loops.

\section{RESULTS}

Karkheh hydro-system analysis results shows that average inflow to Karkheh dam falls to $3523 \mathrm{MCM}$ if all upstream hydro-projects are constructed. Figure3shows yearly simulated inflow to Karkheh dam after all new demands is present in the watershed. Simulation results for Karkheh dam with new inflows, shows that agricultural demand will not satisfied fully and it has considerable deficit of 1628 MCM in future (Table 5).

Karkheh dam downstream agricultural demand supply deficit is 1628 MCM. Upstream and downstream water demands are $3576 \mathrm{MCM}$ and 2914 MCM respectively. Therefore, upstream and downstream stakeholders' shares in agricultural deficit are calculated as 897 MCM and 731 MCM respectively. By these share values, allocated water to upstream and downstream stakeholders become $2679 \mathrm{MCM}$ and $2183 \mathrm{MCM}$ respectively. These total water allocation values for upstream and downstream regions, based on runoff produced in each province (Table 6), are allocated between provinces as shown in table 6 .

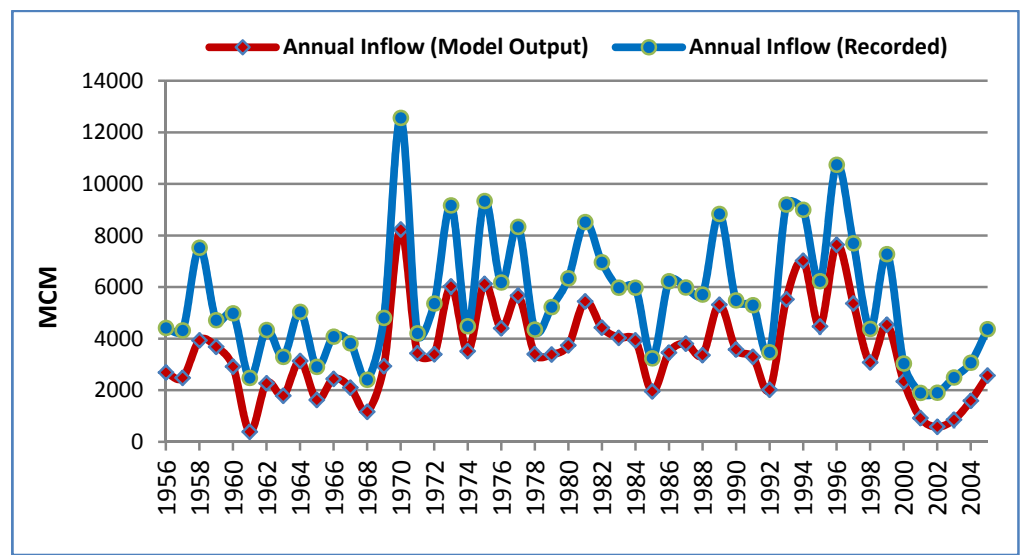

Figure 3.Inflow to Karkheh Dam from 1956 to 2005before and after considering all new demands

Table 5. Simulation results for Karkheh dam considering new water demands in upstream (MCM)

\begin{tabular}{cccccc}
\hline Demand & Initial Target & Reliable Supply & Volumetric Reliability (\%) & Temporal Reliability (\%) & Deficit \\
\hline Environment & 1283 & 1283 & 100 & 100 & 0 \\
Agriculture (Eilam) & 510 & 510 & 90 & 90 & 0 \\
Agriculture (Khozestan) & 2914 & 1286 & 90 & 90 & 1628 \\
Sum & 4707 & 3079 & - & - & 1628 \\
\hline
\end{tabular}


Roozbahani et al., Water Deficit Sharing: A New Approach to Conflict Resolution Among Stakeholders...

Table 6. Runoff produced in upstream provinces and allocated water for them (unit: MCM)

\begin{tabular}{lll}
\hline Province & Runoff Produced (MCM) & Allocated Water (MCM) \\
\hline Hamedan & 546 & 267 \\
Kermanshah & 1644 & 805 \\
Lorestan & 2260 & 1107 \\
Eilam & 1019 & 499 \\
Sum & 5469 & 2679 \\
\hline
\end{tabular}

\section{CONCLUSION}

In this research conflicts about water allocation in the watershed were studied and equitable water allocation was used for resolving these conflicts between upstream and downstream stakeholders. Equitable water allocation seems a suitable choice for governments, since they must distribute development and well-being opportunities equitably amongst all stakeholders. Water deficit sharing, which is based on equitable water allocation concept, was introduced as an approach to conflict resolution about water allocation. In this approach, deficits are shared between stakeholders based on their influence on water deficit all over the water basin. Stakeholders with more impact on water supply deficits, due to increase in stakeholder water demand, have more share of deficit in their water demands.

Water deficit sharing approach is applied to Karkheh hydro-system for water allocation in developing upstream regions, while not impairing downstream water rights and opportunities for development. Water deficit sharing approach, which is a simple and fast method, application to Karkheh watershed shows that $2679 \mathrm{MCM}$ and $2183 \mathrm{MCM}$ allocations are equitable for upstream and downstream, respectively, in developed state of Karkheh watershed. Besides, runoff production ratio to total runoff of each province (as stakeholders in water allocation), which is used as indicator for equitable water allocation between stakeholders suggests $41 \%$ of $2679 \mathrm{MCM}(1107 \mathrm{MCM})$ to be allocated to Lorestan province, since has the largest share in runoff production.

\section{ACKNOWLEDGMENTS}

This study was supported by the Deputy Minister of Energy for Water and Wastewater Affairs and the head of Water Planning Office of Iran Ministry of Energy. The authors are very grateful from their supports and comments on the study.

\section{REFERENCES}

Cai X., Lasdon L., and Michelsen A. M., (2004), Group decision making in water resources planning using multiple objective analysis, Water Resources Planning and Management, 130(1), 4-14.

Chermak, J.M., Patrick, R.H., and Brookshire, D.S. (2005), Economics of transboundary aquifer management, Ground water, 43(5), 731-736.

Dinar A., Rosegrant M.W. and Meinzen-Dick R. (2005), Water Allocation Mechanisms, Principles and Examples, World bank, Agriculture and Natural Resources Dept., Working Paper 1779.

Eleftheriadou E., and Mylopoulos Y., (2008), Game theoretical approach to conflict resolution in transboundary water resources management, Water Resources Planning and Management, 134(5), 466472.

Ganji A, Khalili D, Karamouz M, Ponnambalam K, JavanM, (2008), A fuzzy stochastic dynamic Nash game analysis of policies for managing water allocation in a reservoir system, Water Resources Management, 22, 51-66.

Kampragou E., Eleftheriadou E., and Mylopoulos Y., (2007), Implementing equitable water allocation in transboundary catchments: the case of River Nestos/Mesta, Water Resources Management, 21, 909-918.

Mimi Z. A., and SawalhiB.I., (2003), A decision tool for allocating the waters of the Jourdan River Basin between all riparian parties, Water Resources Management, 17, 447-461.

Nandala K. D. W., and Simonovic S. P., (2003), Resolving conflicts in water sharing: A systemic approach, Water Resources Research, 39(12), 1362-1372.

Shirangi E, Kerachian R, Bajestan MS (2008),A simplified model for reservoir operation considering water quality issues: application of the Young conflict resolution theory, Environmental Monitoring and Assessment, 146, 77-89. 